\title{
Circular Economy and Sustainability of the Tanning Industry
}

\author{
Palumbo G., De Clemente IM*
}

Commodity Science Laboratory, Department of Economics, Management, Institutions University "Federico II" Naples, Campus of Monte S. Angelo, Via Cintia n. 26, Naples 80126

DOI: $10.36347 /$ sjebm.2020.v07i12.003

| Received: 18.11.2020 | Accepted: 01.12.2020 | Published: 13.12.2020

*Corresponding author: De Clemente I.M

Abstract

Review Article

The growing production needs and the demand for products that are increasingly in line with the needs of an evolving company have led to a progressive increase in the complexity of the reference technology, which is inevitably accompanied by a dramatic increase in the environmental impact and, therefore, the loss of the primitive sustainable nature of the sector. In fact, the transformation of putrescible animal integuments into a stable and versatile material such as leather perhaps represents the first example of enhancing a waste in precious raw material, respecting the principles of what we now call circular economy. The current challenge on the sustainability of the tanning production sector therefore requires a set of actions, including the use of efficient certification systems that induce chemical suppliers, tanneries and waste material treatment companies to create a increasingly transparent production flow. Already today there are several companies that have embarked on a path aimed at building a new market system that focuses on sustainability as added value with the ambitious goal of Zero Discharge of Hazardous Chemicals.

Keywords: Tanning industry; Sustainability; Leather, Circular Economy.

Copyright ( $\odot 2020$ The Author(s): This is an open-access article distributed under the terms of the Creative Commons Attribution 4.0 International License (CC BY-NC 4.0) which permits unrestricted use, distribution, and reproduction in any medium for non-commercial use provided the original author and source are credited.

\section{INTRODUCTION}

The tanning industry is very old: the documentary traces of regular tanneries in Palestine date back over 5000 years ago. The tanning production process consists, then as now, of a series of chemical and mechanical treatments which allow the transformation of the raw skin into finished leather, a durable rot-resistant material, hydrothermically stable suitable for its intended uses. Initially, however, the conversion of animal skin into leather was carried out using a few simple chemical compounds with low environmental impact, such as lime, alum, vegetable tannins present in bark, leaves and wood, then vegetable and animal fats and the few natural dyes known. However, in the course of its long history and technological evolution, the tanning industry has had to respond to the demands of a market conditioned both by the needs of an increasing technical performance and by the requests of consumers about leather that were available without aesthetic limitations and, at the same time, durable.

The chemical industry, whose rapid development in relatively modern times, starting from the second half of the 19th century, has responded to these requests and has allowed the tanning industry to draw on a vast repertoire of chemicals, often synthesized ad hoc, capable of conferring to leather practically every desired aesthetic and technological properties. However, this availability has led fatally from the few simple initial chemicals to the more than 300 chemicals currently used in the leather industry: microbiocides, surfactants, masked chromium salts, enzymes, synthetic tannins, synthetic organic dyes, sulfonated fats, synthetic resins, etc.

The first concerns about the environment and human health related to the tanning industry are very ancient and mostly associated with the unpleasant odors, which developed in the ancient tanneries and mainly due to the putrefaction of the fleshings (residues of non-tannable meat ), of the liming water and of other processing waste. But it is only between the end of the $1800 \mathrm{~s}$ and the beginning of the 1900s, through the publication of a series of articles, that fears about the repercussions on the environment and human health of the tanning industry have manifested themselves in a more scientific way; in particular in the second half of the 80 s of the last century the environmental toxicity of compounds such as surfactants was recognized, and especially the carcinogenicity of hexavalent chromium.

The Italian tannery, which produces about $80 \%$ of the production of bovine hides and for the remaining $20 \%$ sheep and goats, has about 1,200 companies and 18,000 workers. The economic model, organized in 
districts, each with its own specialization in production, makes it possible to satisfy all the needs of the market, from the top of the range of leather goods to the low cost couchs of large retailers. It has long held a strong leadership recognized globally, so much that its international relevance is evident both on the export of tanned leather $(26 \%$ of the world trade of finished leather has Italian origins), and on that of imports of materials first, as raw skin or semi-finished leather (20.6\% of international trade has Italy as its final destination).

This is a technologically complex supply chain often considered to cause serious problems of environmental pollution because it is responsible for the use of harmful chemicals, the consumption of large quantities of water, the production of large volumes of effluents with consequent contamination of water bodies and soil and emanation of bad smells. But in reality, environmental protection programs and sustainable strategies have been implemented for a long time to reduce the environmental footprint of leather processing. Indeed, the transformation of putrescible animal integuments into a stable and versatile material such as leather, is perhaps the first example of the valorization of a waste in precious raw material, in compliance with the principles of what we now call the circular economy. Indeed, even before starting its production process, the tanning industry is sustainable because it avoids the disposal of a huge amount of waste of the slaughtery, the animal skins, so reducing the impact on the environment.
The concept of sustainability, already present at the end of the 19th century, is now an essential part of corporate strategies; it represents a necessity that requires an innovative approach, smart, but at the same time oriented towards an effective simplicity. This is not just a concept linked to environmental issues, but refers to the well-being of mankind, highlighting a fundamental aspect: the moral duty to maintain the resources and the balance of the planet in order not to deliver a worse world to future generations compared to the one we are living in. Sustainability therefore also affects health, work, culture, transport, social relations: an ethical and moral duty of companies and consumers. It closely affects consumers, in their daily choices and consumption, and companies whose objectives must be on energy efficiency, consumption reduction, job creation. Some industrial sectors act faster than others in adapting industrial practices to new demands: the Automotive, Design and Fashion sectors are those of which the leather industry, is the key supplier and has been asked to evolve rapidly and develop strategies and techniques to meet modern needs [1].

This is certainly not a new matter in the tanning sector, where the degree of pollution by the produced waste was already a source of concern since the end of the 1800s (Fig. 1); therefore, several actions have been undertaken, some of which are still current today, such as monitoring of effluent, improving of processes, replacement of hazardous chemicals, recycling, recovery and reuse of materials, in order to limit the damage to the environment [2].

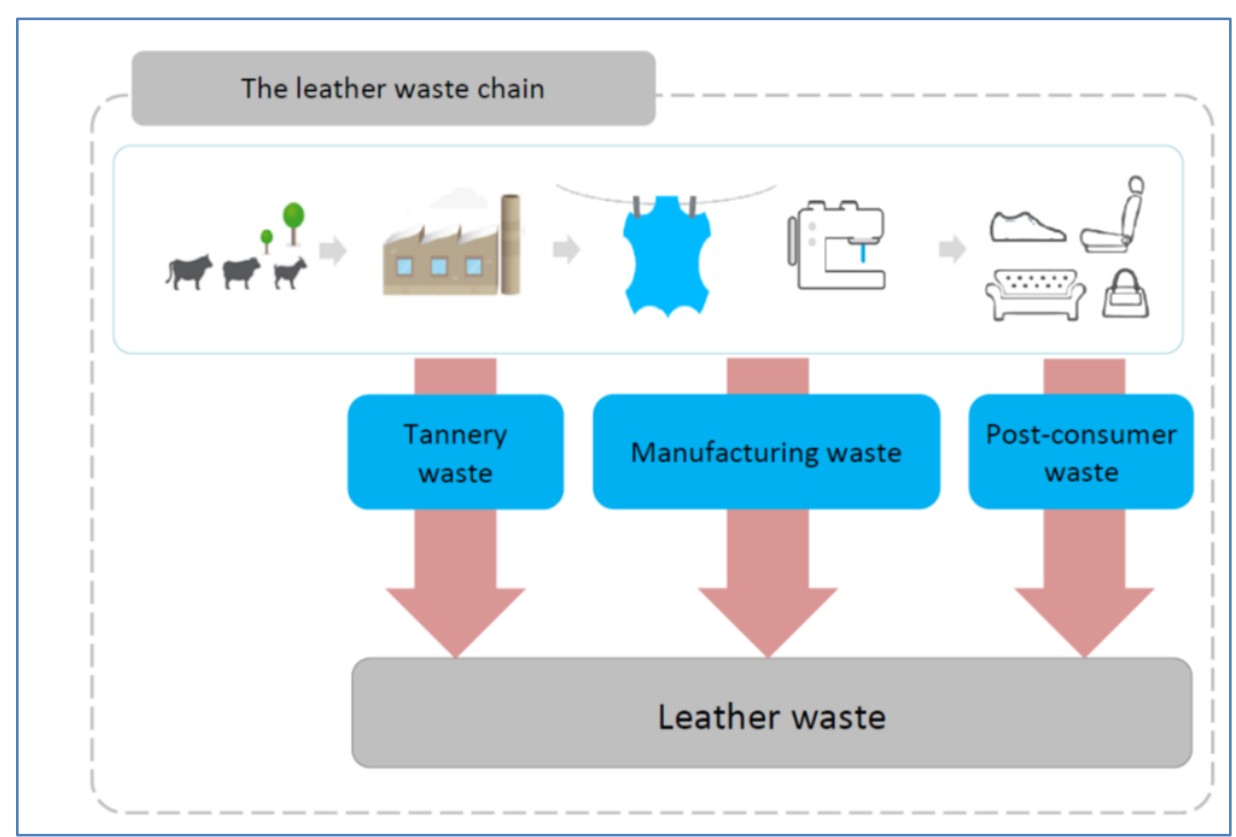

Fig-1: Waste generated at different points within the lifecycle of leather [3]

Undoubtedly, the growing production needs and the demand for products that are more and more responsive to the requirements of an evolving society, have led to a gradual increase in the complexity of the reference technology, which is inevitably accompanied by a dramatic growth in the environmental impact, therefore the loss of the primitive sustainable character of the sector. In order to highlight negative environmental externalities, it is necessary to analyze all the stages of the tanning sector, starting from the origin of the raw 
material, to the design, production, consumption, to the end-of-life destination.

The process of transformation of raw skin into leather. The production process includes a series of chemical and mechanical treatments that allow the transformation of raw skin into finished leather while maintaining its natural structure. The block diagram in
Fig. 2 shows the tanning cycle starting from the phase of soaking of the rawhide to the chrome tanned leather. In particular, the process involves both wet and dry steps. The first include the beamhouse works (soaking, liming, deliming-bating), pickling and the tanning proper; then follow operations of retanning, dyeing and fatliquoring. Dry phases refer to some mechanical operations and to the finishing process.

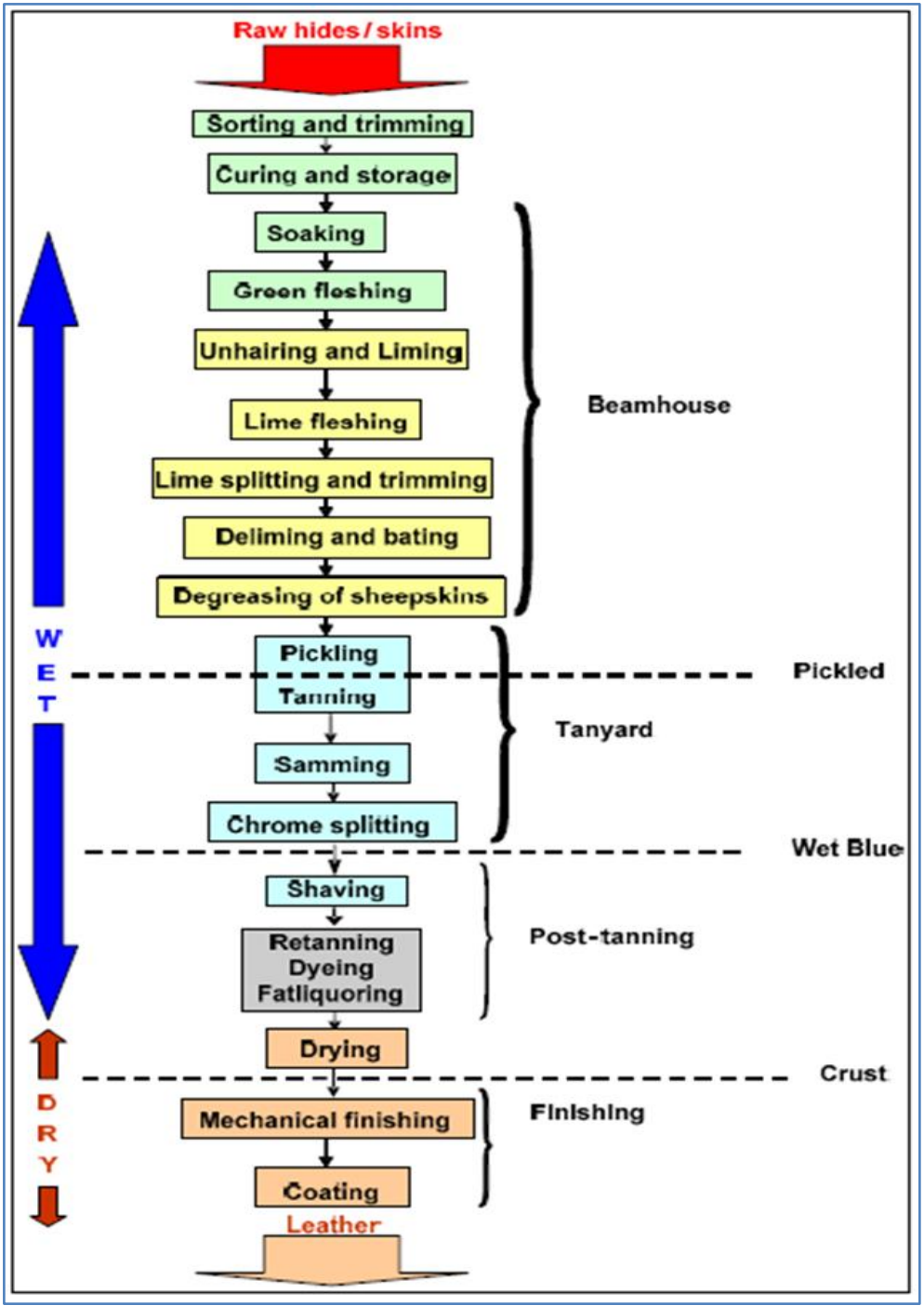

Fig-2: The simplified material flow chart during leather tannery; may be variation depending on the type of leather produced [4]

As everyone can easily imagine from the complexity of the tanning processes reported in the diagram in Fig. 2, the transformation of raw hide into leather also inevitably has an impact on the environment, resulting from the high quantity of waste produced to which is added a share, even if not significant, originating from related and auxiliary activities, such as maintenance; a detailed balance is reported in Fig. 3. More precisely wastes are:

- shavings, cuttings, powders, such as residues of the chemical stabilization process of the leather (tanning), largely recovered and transformed into fertilizers and soil improvers;

- $\quad$ spent tanning baths associated with the recovery activity of chromium salts;

- sludge, as waste of finishing activities, cleaning the tanks and any treatment of waste;

- other sector specific waste, such as salt, absorbent material, filters and process residues, destined for disposal;

- $\quad$ packaging, in paper and plastic, wood and mixed materials, mostly for recovery. 


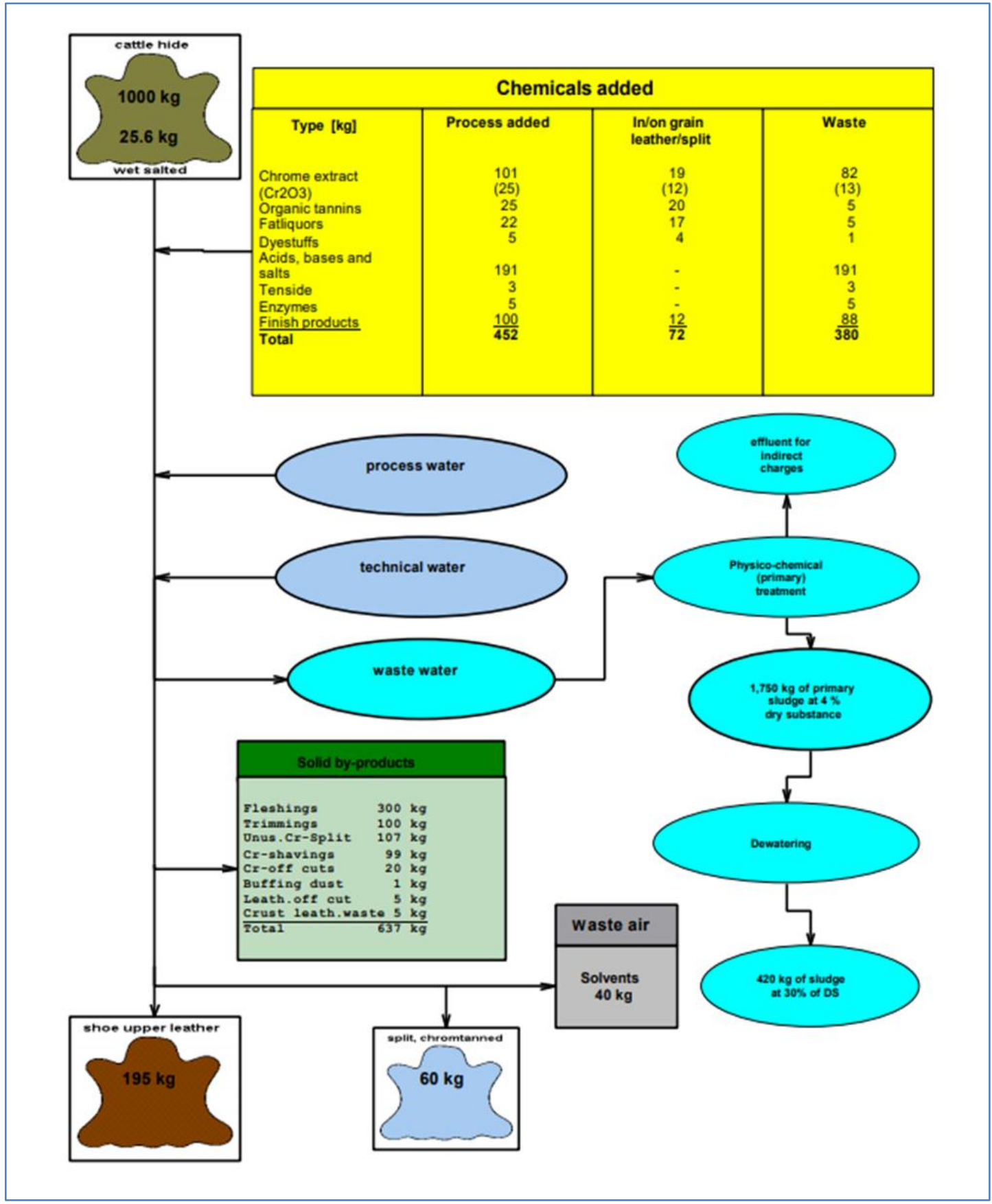

Fig-3: Mass balance for 1 metric ton of bovine raw hide [5]

Waste water purification is necessary due to the presence of high quantities of chemical products that, as such or transformed, remained, as the fixed quantities are almost always lower than those supplied (for example, the fixation yield is $60 \%$ maximum in conventional chrome tanning), mostly the chemical nature is:

- $\quad$ organic substances (even synthetic)
- nitrogen compounds,

- $\quad$ salts, especially chlorides and sulfates,

- $\quad$ sulphides,

- $\quad$ surfactants

The scheme below reported shows the pollution parameters with the differents steps of tanning process. 


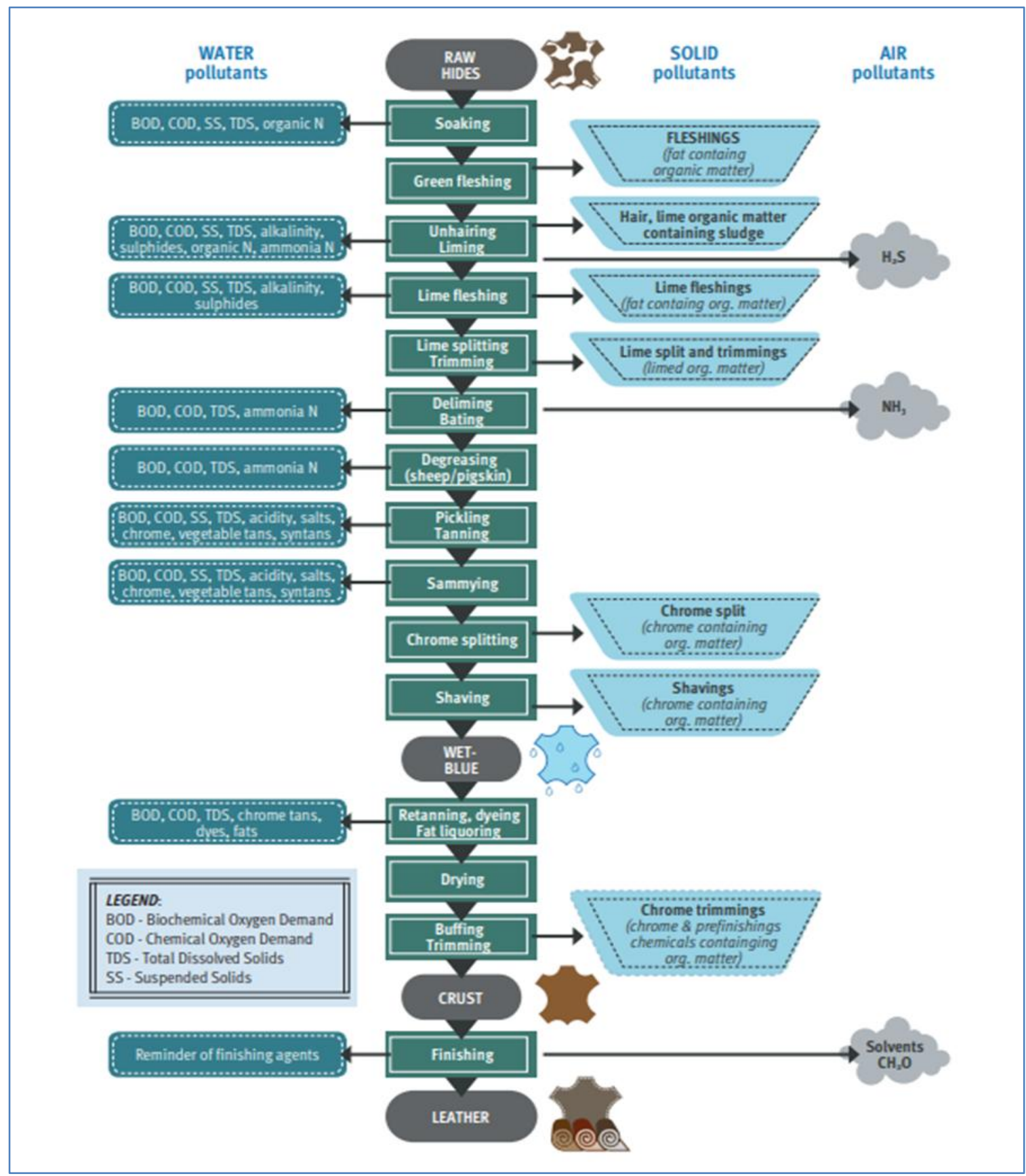

Fig-4: Sources and types of pollutants generated in leather processing [6]

This is the reason therefore the tanning industry is perceived as a highly polluting activity, especially in the case of chrome tanning. In this case commonly is believed that is used hexavalent chromium, certainly toxic and carcinogenic, instead of trivalent chromium, usually used in the tanning process as a basic chromium sulfate. In the trivalent form it does not present particular problems neither on the health plan nor on the environment, because already at a $\mathrm{pH}$ of about 4.5 it is easily separable as hydroxide which is almost inert under normal conditions, even if it must, however, fall within the limits for waste water and solid waste, due to its potential mobility and oxidation to chromium (VI). Likewise, its possible oxidation to hexavalent chromium in finished leather, or following the incineration of processing waste (arising from shaving, grinding, trimming) generates concern. This is the reason why today the terms chrome-free or metal-free are increasingly widespread to indicate leather goods, obtained with organic tanning and without tanning metals, in the common sense believed more easily recyclable, biodegradable and hypoallergenic and preferred, therefore, by those subjects predisposed to allergic phenomena.

The tanning process requires water, energy, and this further aggravates the environmental footprint of the leather supply chain. Water (groundwater, aqueduct water) is the most costly item in the tannery environmental budget, because most of the processes 
take place in aqueous baths, therefore, the use of water resources is a critical factor both from the point of view environmental that economic. Electricity is mainly collected from the network; in some companies it is self-produced through cogeneration or photovoltaic systems in order to reduce costs and waste. The thermal energy required to heat process water and steps that need heat (e.g. drying tunnels) is instead obtained in general from the combustion of natural gas. Finally, in the various stages of transformation to obtain stable and long-lasting leathers, the chemical products are used in aqueous solution in the first phases (baths), and then applied superficially in the final finishing operations. Therefore, there are different initiatives in order to minimize the impact of the sector; indeed, the Italian tannery is investing in technology and research with the installation of new cogeneration plants, heat recovery systems, with the adoption of devices for the optimized dosing of chemicals and water.

\section{circular economy \\ The tanning industry, an example of a} The roots of the circular economy, which has become very fashionable in recent years, can be found in the book "The Closing Circle" (Barry Commoner, 1917-2012) published in the United States in September 1971 and immediately translated by Garzanti in 1972.

The circular economy is based on the concept that in the biological world no waste is produced: by an inescapable law of nature every living creature"lives" by absorbing energy and materials from the surrounding environment which, after the necessary transformations, are returned to the same environment: everything that is taken from nature is returned to nature, in more or less long times, more or less in the same quantity. We ourselves "buy", it does not matter whether in money or not, plant and animal food and water and gas from the atmosphere, we transform them into vital, muscular energy, and we expel, "we refuse", externally, in the form of excrement, or breathing gas, (almost) all that we absorbed. Biological cycles are, therefore, by definition, "closed" in their exchanges, in and out, with the natural environment [7].

But human beings derive from nature not only vegetable and animal raw materials, but also other materials such as minerals, rocks, fossil fuels, and transform them into the most varied goods, extraneous to natural cycles, which once used are thrown away, become waste, but they do not disappear because the soil and water decomposing organisms do not know them, they are not able to degrade them and waste accumulates in the technosphere which, in the "swelling" of goods, also "swells" with waste, from solid ones, to gases that, accumulating in the atmosphere, they create the known climatic anomalies. Their disposal or possible recovery therefore becomes necessary if they contain something useful that can be recovered and traded. These are the recycling activities, known from very distant times when rags, scrap and slaughterhouse bones were recycled and which today are the object of the circular economy. These activities are certainly useful and subject to continuous improvement because the residues of industrial production, of agriculture itself and of "consumption" amount, in the world, to a few billion tons per year. It is an example of nature to follow but with rationality, in fact, we must not delude ourselves too much because all the circular economy operations generate, in turn, other waste and slag and the cycle never ends [8].

For years the Italian tanning industry has made investments and records, without direct contact with consumers (like many semi-finished manufacturers) and without making it clear that the processing of leather for bags, shoes, sofas, car and yacht interiors is not it is only an excellence of the country (which is in fact the absolute leader in Europe) but it is also a sector that has applied the principles of the circular economy for a long time, which is so much talked about today, from recycling to recovery [9].

The availability of raw hides on the market does not depend on the needs of the tanning manufacturing industry, but on the slaughtering activity, a fundamental activity for human food needs. The leather industry poses, first of all, as an environmentally sustainable solution to the problem of disposing of large quantities of by-products of the slaughtering industry: that is, it transforms waste into a material of excellence, leather, whose versatility is fundamental in the world of fashion, furniture, design and car interiors. This is a typical example of an economically circular model: waste becomes the raw material for the tanning industry itself, which in turn feeds other production processes (such as production of "regenerated" leather fibers, small leather accessories, or transformation into fertilizers of high agronomic value, proteins and collagen for food use) thus virtuously closing the cycle of elements.

In particular, since they are biological waste, with suitable technological processes it is possible to obtain hydrolyzed proteins from the skin, from which special fertilizers (biostimulants), totally biodegradable, can be used without risk for public health and the environment. Processes of thermal or enzymatic hydrolysis on other scraps, also already tanned (shaving, trimming, etc), allow obtaining, even in this case, high quality fertilizers and agronomic efficiency. Their regular use allows maintaining or increasing the fertility of the agricultural land and improving its structure, similar to the mature manure.

From pelt scabs and splits, but also tanned scraps, rich in proteins, it is possible to obtain some products, such as collagen, artificial casings, jellies and proteins, to be used in the food chain. Since it is a material intended for human consumption, it must satisfy the health and 
hygiene requirements so as to guarantee food safety. The by-products, unfit for human consumption, can be transformed into technical jellies, glues, pet food and edible pet toys.

Also the sewage sludge can be reused in agriculture, given the consistent presence of organic substances deriving from natural extracts of vegetable origin (tannins) in the case of vegetable tanning, the high amount of organic substance of protein origin deriving from the hides, the presence of residues derived from components such as fur, hair, flesh, etc., already recognized individually as fertilizers. Some mixed fertilizers (N-P) have also been developed, mixing the "Pellicino Integrato ", with other animal by-products (meat flours, bone meal, etc.), which are already treated to be suitable for use. For example, in 2016, starting from the sewage sludge, 20,500 metric tons of organonitrogen fertilizers were produced and sold.

Finally, by means of the dehydration and drying of the sludge, by means of the pyrosintering, a sintered granulate can be obtained (called KEU) which, after mixing with calcium carbonate, is used for the production of aggregate granulates for the building industry and asphalt mixtures for road surface, thus closing a virtuous circle with the reuse of sludge as the second raw material. This has allowed the decrease in the volumes of sludge deriving from purification treatments and destined for disposal, passed in 20 years (1995 - 2015) from 180,000 to 15,000 tons per year [10].

Also in the context of recovery processes in the leather industry, a problem faced over time is the one related to solid chrome tanning waste, the CTLW (Chromium Tanned Leather Waste), i.e. all those residues such as trimming, dust of grinding, etc, with a percentage of chromium that varies, on dry matter basis, from 2 to over $4 \%$ calculated as $\mathrm{Cr}_{2} \mathrm{O}_{3}$ and a percentage of organically combined total nitrogen (TKN - Total Kjeldhal Nitrogen) between 14 and $20 \%$.

The treatment of this waste not only allows the recovery of chromium, but also the extraction of its protein fraction as hydrolyzed collagen or gelatin. Various treatments have been proposed for the recovery of these materials, among the most promising ones because they are less impactful for the environment, more economically advantageous and because they guarantee a higher recovery, as well as a better exploitation of protein fractions, for relatively mild operating conditions. there is the one that use an alkaline hydrolysis at temperatures of the order of $70-90{ }^{\circ} \mathrm{C}$ and lasting some hours. The bases used are generally magnesium oxide or calcium oxide, more rarely combinations of sodium hydroxide / magnesium oxide. For animal jelly, applications range from use as microencapsulants, finishing agents for leather, products for animal feeding, to applications in the cosmetics, photographic, adhesive sectors, etc. For the other recoverable organic fraction, the collagen hydrolyzate, on the other hand, applications such as tanning agent, organic nitrogen fertilizer, base for biodegradable polymers for agricultural uses, adhesives, cementitious additives, hydrogels, etc. have been suggested or tested. Naturally, the recovery process also leads to an inorganic mass ("cake") with a high chromium content from which basic chromium salts can be synthesized again for tanning use, otherwise the cake that can also be used for other applications: glassmaking, ceramics, etc. [11].

The linear economic model 'take-make-dispose' less and less adapts itself to the reality in which we find ourselves operating. The current challenge on the sustainability of the tanning production sector requires a set of actions, including the use of efficient certification systems that encourage suppliers of chemical products, tanneries and waste material treatment companies to achieve a production flow increasingly transparent and traceable [12]. Already today there are several companies that have embarked on a path aimed at realizing a new market system that puts sustainability at the center as an added value, with the ambitious goal of Zero Discharge of Hazardous Chemicals. The Circular Economy model finds more and more confirmations of its validity as a winning strategy if properly implemented in a technologically complex and constantly evolving supply chain, which is currently the tanning one and to provide the operative tools to aim in a new and systemic way at reducing the consumption of raw, water and energy, according to the model of the four R's: Reduction, Reuse, Recycling and Recovery [13].

\section{ACKNOWLEDGMENTS}

The authors are grateful to Buljan J., Reich G., Ludvik J. and I. Král' for making freely available and usable their valuable documents on Internet.

\section{REFERENCES}

1. Brugnoli F. Sustainability in the Leather Value Chain: Global Overview, Regional and Sectoral Peculiarities. Journal of the American Leather Chemists Association. 2017 Sep 1;112(09):286-93.

2. Lama A, Casey J. Concept of sustainability: lookingforward, Leather. AGE; March; 2018.

3. Pringle T. Establishing a Circular Economy Approach for the Leather Industry. Doctoral Thesis Loughborough University; 2017.

4. Joint Research Centre. Best Available Techniques (BAT) Reference Document for the Tanning of Hides and. .Skins;..p.1314.;2013.available.from: http://wiki.zeroemissions.at/index.php?title=Inform ation_about_hides_and_skins.

5. Buljan J, Reich G, Ludvik J. Mass balance in leather processing. United Nations industrial development Organization. Regional Programme for Pollution Control in the Tanning Industry in South-East Asia. 2000 Aug 9. 
6. Buljan J, Král' I. The framework for sustainable leather manufacture. Second edition, UNIDO; 2019.available.from: https://leatherpanel.org/sites/default/files/publicatio ns.attachments/the_framework_for_sustainable_lea ther_manufacturing_2nd_edition_2019_f.pdf

7. Nebbia G. Breve storia dei rifiuti. Altronovecento; n. $19 ; 2012$.

8. Nebbia G. Alla ricerca delle origini dell'economia circolare. Greenreport.it; 2018.

9. Pieraccini S. L'industria conciaria è già a prova di circular economy. Il sole24ore; 2019.

10. Unione Nazionale Industria Conciaria (UNIC). Rapporto di Sostenibilità. 2017.
11. Scopel, B.S., et al. Hydrolysis of Chromium Tanned Leather Waste: Turning Waste into Valuable materials. A Review, JALCA, vol.113; 2018.

12. Gurisatti P. Tracciabilità e trasparenza condizioni dell'economia circolare. Il caso della filiera pelle. Il festival della Green economy, Green Week, Trento 17 marzo 2018.

13. Palumbo G, De Clemente I.M. The model of the Circular Economy as a strategy for the sustainability of the tanning industry. Oral communication at the XXI IGWT Symposium; 2018 . 